\title{
Myocardial revascularization in infants and children by means of coronary artery proximal patch arterioplasty or bypass grafting: A single-institution experience
}

Eric Bergoënd, MD, ${ }^{a}$ Olivier Raisky, MD, ${ }^{a}$ Alexandra Degandt, MD, ${ }^{a}$ Daniel Tamisier, MD, ${ }^{a}$ Daniel Sidi, MD, ${ }^{\text {b }}$ and Pascal Vouhé, MD ${ }^{a}$

From the Departments of Pediatric Cardiac Surgery ${ }^{\mathrm{a}}$ and Pediatric Cardiology, ${ }^{\mathrm{b}}$ Hôpital Necker-Enfants Malades, Paris, France.

Read at the Eighty-seventh Annual Meeting of The American Association for Thoracic Surgery, Washington, DC, May 5-9, 2007.

Received for publication June 13, 2007; revisions received Feb 5, 2008; accepted for publication Feb 26, 2008.

Address for reprints: Pascal Vouhé, MD, Department of Pediatric Cardiac Surgery, Hôpital Necker-Enfants Malades, 149 rue de Sèvres, 75015 Paris, France (E-mail: pascal.vouhe@nck.ap-hop-paris.fr).

J Thorac Cardiovasc Surg 2008;136:298306

$0022-5223 / \$ 34.00$

Copyright (C) 2008 by The American Association for Thoracic Surgery

doi:10.1016/j.jtcvs.2008.02.059
Objective: We sought to evaluate midterm functional and anatomic results after coronary artery surgical arterioplasty or bypass grafting in infants and children.

Methods: Data concerning all consecutive patients operated on for myocardial revascularization in our institution between 1992 and 2004 were retrospectively analyzed.

Results: Twenty-five patients (mean age, 5.3 years) underwent surgical arterioplasty of a main coronary trunk, and this was for coronary obstruction after the arterial switch operation in 19 patients. Eight patients (mean age, 8.0 years) underwent a coronary bypass, and this was for postoperative coronary obstruction in all of them. One patient died 4 days after arterioplasty because of cardiogenic shock. One patient died suddenly 3.5 months after bypass from an unknown cause. All other patients were alive after a mean follow-up of 3.4 years after arterioplasty and 4.4 years after bypass. Among the 3 patients in whom the surgical enlargement of the left main trunk was extended to the left anterior descending coronary artery, 2 presented a restenosis of this artery and necessitated a coronary bypass 2.6 and 5.7 years, respectively, after arterioplasty. Among patients who had a postoperative angiogram, 17 (89\%) of 19 after arterioplasty and $3(50 \%)$ of 6 after bypass showed a good result. A internal thoracic artery graft was occluded, another one showed a complete string sign, and, finally, a patient presented with a tight stenosis of the bypass distal anastomosis. Eighteen $(72 \%)$ patients after arterioplasty and 5 (63\%) after bypass remained symptom free at last follow-up.

Conclusions: Provided that the left main coronary artery bifurcation was not involved in the stenotic process, surgical arterioplasty of the main coronary trunks led to good functional and anatomic midterm results. On the other hand, variable indications and poorer preoperative cardiac conditions might have contributed to the disappointing results observed after coronary bypass.

A lthough indications for myocardial revascularization remain rare in children in our experience, use of the arterial switch operation (ASO) as the treatment of choice for transposition of the great arteries has increased the incidence of ostial and proximal coronary lesions. ${ }^{1,2}$ We have therefore investigated patients on a systematic basis after ASO and operated on those with severe stenosis of a major coronary trunk and evidence of myocardial ischemia. ${ }^{3}$ This situation is challenging for several reasons. First, expertise has to be gained for reliable assessment of myocardial ischemia and viability in children. Second, when surgical intervention is indicated, one can choose between 2 revascularization techniques: surgical arterioplasty (coronary artery proximal patch arterioplasty [CAPPA], Figure 1) or coronary artery bypass grafting $(\mathrm{CABG})$, a more conventional treatment.

The advantages of CAPPA are that it saves use of bypass material and restores a more physiologic and thus possibly more efficient antegrade flow and also facilitates further catheterization of the coronary arteries if needed. On the other hand, problems with CABG in children can include occlusion of the left main coronary artery (LMCA), retrograde perfusion of a wide myocardial area when only 1 bypass graft 


$$
\begin{aligned}
& \text { Abbreviations and Acronyms } \\
& \begin{aligned}
\text { ASO } & =\text { arterial switch operation } \\
\text { CABG } & =\text { coronary artery bypass grafting } \\
\text { CAPPA } & =\text { coronary artery proximal patch arterioplasty } \\
\text { CPB } & =\text { cardiopulmonary bypass } \\
\text { ICU } & =\text { intensive care unit } \\
\text { ITA } & =\text { internal thoracic artery } \\
\text { LAD } & =\text { left anterior descending coronary artery } \\
\text { LITA } & =\text { left internal thoracic artery } \\
\text { LMCA } & =\text { left main coronary artery } \\
\text { PA } & =\text { pulmonary artery } \\
\text { RCA } & =\text { right coronary artery } \\
\text { RV } & =\text { right ventricle }
\end{aligned}
\end{aligned}
$$

is constructed, and the presence of an internal thoracic artery (ITA) graft behind the sternum, which can put patients undergoing reoperation at higher risk. However, internal thoracic artery bypass has the major advantage that longer followup with good results has been reported since the late 1970s in Japanese populations affected by coronary complications of Kawasaki disease. ${ }^{4,5}$

The present article reports our assessment of the functional and anatomic midterm results achieved with both CAPPA and CABG in infants and children in our institution.

\section{Materials and Methods}

We reviewed the records of all consecutive infants and children who underwent a surgical myocardial revascularization in Hôpital Laennec-Necker, Paris, France, between January 1, 1992, and December 31,2004 . Primary repair of anomalous pulmonary or aortic origins of coronary arteries were excluded. This study was approved by the local ethics committee. Characteristics of patients are shown in Tables 1 and 2 .

\section{Population}

Twenty-five patients (mean \pm standard deviation age, $5.3 \pm 4.4$ years; range, 1 month to 15.9 years) underwent a CAPPA: 19 of the LMCA, 2 of an isolated left anterior descending coronary artery (LAD), 3 of the right coronary artery (RCA), and 1 of both the LMCA and RCA. Indications were postoperative coronary obstruction in 22 patients: 19 after arterial switch for transposition of the great arteries, 2 after direct aortic reimplantation of the anomalous left coronary artery originating from the pulmonary artery (PA), and 1 after direct aortic reimplantation of a left coronary artery with anomalous connection to the right aortic sinus. The indication was congenital LMCA stenosis associated with supravalvar aortic stenosis in 3 patients (all 3 had Williams syndrome).

Eight patients (mean age, $8.0 \pm 4.1$ years; range, $2.6-13.0$ years) had a CABG, including 6 left internal thoracic artery (LITA)-LAD grafts. Indications were postoperative coronary obstruction in all patients. Patient 30 presented with an obstruction of the LAD originating from the RCA underneath a right ventricle (RV) to PA conduit inserted during the repair of a tetralogy of Fallot. Patient 32 had a modified Konno operation and right ventricular outflow tract enlargement for hypertrophic cardiomyopathy associated with the repair of an anomalous aortic origin of the RCA with intramural course. Patient 33 had a modified Bentall procedure and RV-PA conduit replacement after a neonatal repair of type I truncus arteriosus; he presented postoperatively with complete heart block and severe ischemic cardiomyopathy and underwent technically challenging CABG for LMCA occlusion 1 year later. Finally, patient 31 had a myocardial infarction at the end of a Ross procedure and required an emergency internal thoracic artery grafting to the LAD.

The coronary anatomy distribution for the patients who underwent an ASO was as follows: a usual coronary anatomy in 14 patients; coronary patterns with anterior loops, posterior loops, or both in 6 patients; and coronary arteries coursing between the great arteries in 1 patient. Four patients (nos. 5, 16, 17, and 26) had, during the ASO, a particular technique of coronary transfer in which the coronary ostia were reimplanted side-by-side in the neoaorta (single-orifice technique) ${ }^{7}$; this technique was abandoned after 1993 because of a high incidence of coronary obstruction. ${ }^{8}$ The median interval between ASO and myocardial revascularization was 6.0 years (range, 28 days to 13.5 years). It was 2.6 years (range, $1-9.4$ years) for other operations.

\section{Indication for Revascularization}

Surgical intervention was indicated when a significant coronary obstruction was associated with findings suggestive of myocardial

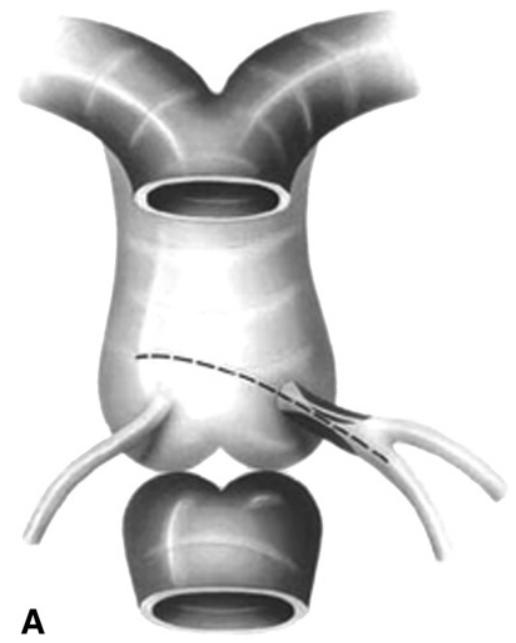

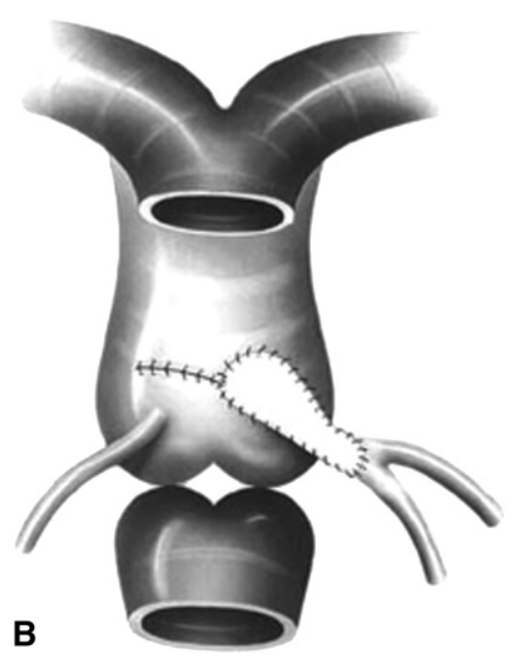

Figure 1. Left main coronary artery proximal patch arterioplasty. $A$, The main pulmonary trunk is transected to allow adequate exposure of the aortic root and left main stem. $B$, The aorta is opened anteriorly, and the incision is extended across the coronary obstruction up to a normal arterial wall. An onlay patch is used to enlarge not only the main coronary stem but also the adjacent aortic incision to give the new coronary ostium a funnel shape. 
TABLE 1. Preoperative characteristics of patients undergoing CAPPA (patients 1-25) and CABG (patients 26-33)

\begin{tabular}{|c|c|c|c|c|c|}
\hline \multirow[b]{2}{*}{ Patient no. } & \multirow[b]{2}{*}{ Indication } & \multirow[b]{2}{*}{ Symptoms } & \multicolumn{2}{|c|}{ Myocardial ischemia } & \multirow[b]{2}{*}{$\begin{array}{l}\text { Angiographic } \\
\text { findings }\end{array}$} \\
\hline & & & $\begin{array}{c}\text { ECG and/or } \\
\text { echocardiography }\end{array}$ & MPI & \\
\hline 1 & After ASO (type A) & Mild & + & PD & LMCA stenosis \\
\hline 2 & After ASO (type A) & Chest pain & + & PD & LMCA stenosis \\
\hline 3 & After ASO (type A) & Moderate & + & PD & LMCA stenosis \\
\hline 4 & After ASO (type E) & None & - & PD & LMCA stenosis \\
\hline 5 & After ASO (type A) & Mild & + & PD & LMCA occlusion \\
\hline 6 & After ASO (type D) & None & - & PD & $\begin{array}{l}\text { LAD occlusion } \\
\text { (direct aortic origin) }\end{array}$ \\
\hline 7 & After ASO (type A) & Mild & + & PD & LMCA stenosis \\
\hline 8 & After ASO (type A) & None & + & PD & LMCA occlusion \\
\hline 9 & After ASO (type A) & None & + & PD & LMCA ostial stenosis \\
\hline 10 & After ASO (type A) & Moderate & + & PD & LMCA stenosis \\
\hline 11 & After ASO (type E) & None & + & PD & LMCA occlusion \\
\hline 12 & After ASO (type A) & None & + & PD & LMCA stenosis \\
\hline 13 & After ASO (type A) & Mild & + & PD & LMCA stenosis \\
\hline 14 & After ASO (type C) & Mild & + & PD & LMCA stenosis \\
\hline 15 & After ASO (type D) & Mild & + & PD & $\begin{array}{l}\text { LAD occlusion } \\
\text { (direct aortic origin) }\end{array}$ \\
\hline 16 & After ASO (type A) & None & + & PD & RCA stenosis \\
\hline 17 & After ASO (type E) & None & + & PD & RCA stenosis \\
\hline 18 & After ASO (type A) & \multicolumn{2}{|c|}{$\begin{array}{l}\text { Persistent myocardial ischemia on } \\
\text { ECG and echocardiography }\end{array}$} & - & $\begin{array}{l}\text { Aortic root } \\
\text { angiogram exhibit } \\
\text { equivocal results }\end{array}$ \\
\hline 19 & After ASO (type A) & Syncope during exercise & + & PD & LMCA stenosis \\
\hline 20 & Williams syndrome & Mild & + & - & LMCA stenosis \\
\hline 21 & Williams syndrome & Mild & + & - & LMCA stenosis \\
\hline 22 & Williams syndrome & Cardiac arrest during anesthesia & + & PD & $\begin{array}{l}\text { LMCA and LAD } \\
\text { stenosis }\end{array}$ \\
\hline 23 & After ALCAPA repair & Moderate & + & PD & LMCA ostial stenosis \\
\hline 24 & After ALCAPA repair & Syncope during exercise & + & PD & LMCA occlusion \\
\hline 25 & After AAOC repair & Mild & + & $\begin{array}{l}\text { Fainted during } \\
\text { exercise }\end{array}$ & LMCA stenosis \\
\hline 26 & After ASO (type A) & Mild & + & PD & LMCA stenosis \\
\hline 27 & After ASO (type D) & None & + & PD & $\begin{array}{l}\text { LAD occlusion } \\
\text { (direct aortic origin) }\end{array}$ \\
\hline 28 & After CAPPA (patient 12) & Mild & + & PD & LAD proximal stenosis \\
\hline 29 & After CAPPA (patient 22) & Mild & + & PD & $\begin{array}{l}\text { Critical tubular } \\
\text { stenosis of the LAD }\end{array}$ \\
\hline 30 & After TOF repair & Chest pain & + & PD & $\begin{array}{l}\text { LAD stenosis } \\
\text { (originating from } \\
\text { RCA) }\end{array}$ \\
\hline 31 & Emergency $\mathrm{CABG}^{*}$ & Severe LV dysfuncti & on TOE & - & - \\
\hline 32 & After AAOC repair & Syncope during exercise & + & PD & RCA stenosis \\
\hline 33 & $\begin{array}{l}\text { After modified } \\
\text { Bentall procedure }\end{array}$ & Cardiac failure & + & PD & LMCA occlusion \\
\hline
\end{tabular}

CAPPA, Coronary artery proximal patch arterioplasty; $C A B G$, coronary artery bypass grafting; ECG, electrocardiography; $M P I$, myocardial perfusion imaging studies; $A S O$, arterial switch operation (coronary anatomy distribution, classification of Yacoub and Radley-Smith ${ }^{6}$ ); $P D$, perfusion defect; $L M C A$, left main coronary artery; $L A D$, left anterior descending coronary artery; $A L C A P A$, anomalous left coronary artery from the pulmonary artery; $A A O C$, anomalous aortic origin of coronaries; $T O F$, tetralogy of Fallot; $R C A$, right coronary artery; $L V$, left ventricular; $T O E$, transesophageal echocardiography. ${ }^{*}$ Emergency coronary artery bypass grafting to wean a patient from cardiopulmonary bypass at the end of a Ross operation. 
TABLE 2. Operative and postoperative characteristics of patients undergoing CAPPA (patients 1-25) and CABG (patients 26-33)

\begin{tabular}{|c|c|c|c|c|c|}
\hline \multirow[b]{2}{*}{ Patient no. } & \multirow[b]{2}{*}{$\begin{array}{l}\text { Surgical } \\
\text { procedure }\end{array}$} & \multirow[b]{2}{*}{$\begin{array}{c}\text { Age at } \\
\text { operation (y) }\end{array}$} & \multirow[b]{2}{*}{ Status } & Postoperative & \multirow[b]{2}{*}{$\begin{array}{l}\text { Angiographic } \\
\text { findings }\end{array}$} \\
\hline & & & & $\begin{array}{c}\text { MPI and } \\
\text { echocardiography }\end{array}$ & \\
\hline 1 & LM-CAPPA & 4.0 & On diuretics & Normal & Normal \\
\hline 2 & LM-CAPPA & 7.4 & Symptom free & Normal & Normal \\
\hline 3 & LM-CAPPA & 8.6 & On ACE inhibitors & $\begin{array}{l}\text { Residual PD, lateral } \\
\quad \text { hypokinesis, SF }=27 \%\end{array}$ & Normal \\
\hline 4 & LM-CAPPA & 7.5 & Symptom free & Normal & Normal \\
\hline 5 & LM-CAPPA & 5.4 & Symptom fee & Normal & Normal \\
\hline 6 & LAD-CAPPA & 10.0 & Symptom free & Normal & Normal \\
\hline 7 & LM-CAPPA & 0.2 & Symptom free & Normal & Normal \\
\hline 8 & LM-CAPPA & 7.4 & Symptom free & Normal & - \\
\hline 9 & LM-CAPPA & 0.4 & Symptom free & Small residual PD & - \\
\hline 10 & LM-CAPPA & 0.5 & Symptom free & Normal & Normal \\
\hline 11 & LM-CAPPA & 8.0 & Symptom free & Normal & Normal \\
\hline 12 & LM-CAPPA & 7.6 & $\begin{array}{l}\text { Reoperation } \\
\quad \text { (patient 28) }\end{array}$ & Apical PD & $\begin{array}{l}\text { Normal LMCA, stenosis } \\
\text { of the LAD }\end{array}$ \\
\hline 13 & LM-CAPPA & 0.5 & Symptom free & Normal & Normal \\
\hline 14 & LM-CAPPA & 1.9 & Symptom free & Normal & Normal \\
\hline 15 & LAD-CAPPA & 4.8 & Symptom free & Normal & Normal \\
\hline 16 & R-CAPPA & 10.3 & Symptom free & Normal & Normal \\
\hline 17 & R-CAPPA & 6.1 & Symptom free & Normal & Normal \\
\hline 18 & R-CAPPA & 0.1 & Perioperative death & - & - \\
\hline 19 & LM + R-CAPPA & 15.9 & Symptom free & Normal & Normal \\
\hline 20 & LM-CAPPA & 0.5 & Lost to follow-up & - & - \\
\hline 21 & LM-CAPPA & 0.3 & Symptom free & Normal & - \\
\hline 22 & LM-CAPPA & 2.9 & $\begin{array}{l}\text { Reoperation } \\
\quad \text { (patient 29) }\end{array}$ & $\begin{array}{l}\text { Large anterior PD, } \\
\text { LV dysfunction }\end{array}$ & $\begin{array}{r}\text { Normal LMCA, severe } \\
\text { stenosis of the LAD }\end{array}$ \\
\hline 23 & LM-CAPPA & 1.7 & On ACE inhibitors & $\begin{array}{l}\text { Limited lateral PD } \\
\text { and hypokinesis, } \\
\text { moderate MR }\end{array}$ & - \\
\hline 24 & LM-CAPPA & 9.2 & Symptom free & Normal & Normal \\
\hline 25 & LM-CAPPA & 12.1 & Symptom free & Normal & Normal \\
\hline 26 & LITA-LAD & 3.1 & Symptom free & Normal & Normal \\
\hline 27 & LITA-LAD & 10.7 & Symptom free & Normal & Normal \\
\hline 28 & LITA-LAD & 10.2 & Symptom free & Normal & Normal \\
\hline 29 & LITA-LAD & 8.7 & Symptom free & $\begin{array}{l}\text { Anterior PD, } \\
\text { mild dyskinesis }\end{array}$ & Graft occlusion \\
\hline 30 & LITA-LAD & 11.6 & Symptom free & Normal & String sign \\
\hline 31 & LITA-LAD & 13.0 & On ACE inhibitors & $\begin{array}{l}\text { Anterior hypokinesis, } \\
\quad \text { SF }=20 \%\end{array}$ & - \\
\hline 32 & RITA-RCA & 2.6 & $\begin{array}{l}\text { Sudden death } 3.5 \text { mo } \\
\text { after operation }\end{array}$ & - & - \\
\hline 33 & $\mathrm{CABG}^{*}$ & 3.9 & Severe heart failure & Dilated cardiomyopathy & $\begin{array}{l}\text { Stenosis of the distal } \\
\text { anastomosis }\end{array}$ \\
\hline
\end{tabular}

CAPPA, Coronary artery proximal patch arterioplasty; $C A B G$, coronary artery bypass grafting; $M P I$, myocardial perfusion imaging studies; $L M-C A P P A$, left main-coronary artery proximal patch arterioplasty; $A C E$, angiotensin-converting enzyme; $P D$, perfusion defect; $S F$, shortening fraction; $L A D-C A P P A$, left anterior descending coronary artery-coronary artery proximal patch arterioplasty; $L M C A$, left main coronary artery; $L A D$, left anterior descending coronary artery; $R-C A P P A$, right-coronary artery proximal patch arterioplasty; $L V$, left ventricular; $M R$, mitral regurgitation; $L I T A-L A D$, left internal thoracic artery-left anterior descending coronary artery grafting; RITA-RCA, right internal thoracic artery-right coronary artery grafting. ${ }^{*}$ Free left subclavian artery to left anterior descending coronary artery grafting.

ischemia. Some patients were asymptomatic at the time of diagnosis, with no signs of ischemia either on electrocardiographic, echocardiographic, or scintigraphic analysis; coronary lesions were found incidentally during routine coronary angiography. These patients were treated medically, and revascularization was delayed until an obvious ischemia could be shown. In addition, 
fluorodeoxyglucose-positron emission tomography demonstrated myocardial viability in 3 patients (nos. 3, 27, and 33) in whom redistribution was incomplete at rest within the area of the perfusion defect. The mean interval between the diagnosis of coronary obstruction and myocardial revascularization was $23.4 \pm 34$ months (range, 8 days to 8.5 years); the median interval was 4.7 months.

\section{Surgical Technique}

Surgical arterioplasty (Figure 1). After median resternotomy, standard cardiopulmonary bypass (CPB) was established, the aorta was crossclamped, and myocardial preservation was achieved through hot-induction blood cardioplegia, repeated cold blood cardioplegia, and warm reperfusion. In recent years, CPB was conducted on normothermia with repeated hot blood cardioplegia. For left coronary artery arterioplasty, in patients with normally related great vessels, as well as in patients with previous translocation of the great arteries, the main pulmonary trunk was transected, and both pulmonary stumps were freed from the surrounding structures to allow adequate exposure of the aortic root and left main stem. The incision was started on the anterior aspect of the aortic root and was extended toward the involved coronary ostium. In stenotic lesions the incision was extended across the stenotic area until a normal coronary artery wall was reached. In 3 patients (nos. 5, 12, and 22) the incision was extended to the LAD. In occluded lesions the left main stem beyond the obstruction was opened, and both aortic and coronary incisions were joined together across the occluded area. An onlay patch was used to enlarge not only the main coronary stem but also the adjacent 1 to $2 \mathrm{~cm}$ of the aortic incision to give the new coronary ostium a funnel shape. The remaining aortic incision was closed directly. A saphenous vein patch was used in 19 patients, and a fresh autologous pericardial patch was used in 3 patients; the patch was tailored in the innominate vein in 2 patients, and expanded polytetrafluoroethylene onlay patches were used in patient 19. When supravalvar aortic stenosis was associated with coronary obstruction, the sinotubular junction was enlarged between all 3 commissures by using 3 separate patches of pericardium (3-patch repair), and in the left aortic sinus the incision was extended toward the roof of the LMCA.

$\boldsymbol{C A B G}$. Standard techniques were used for internal thoracic artery dissection and anastomoses. Those anastomoses were made with 8-0 monofilament running sutures. In patient 27 the internal thoracic artery was anastomosed end-to-end to a transected LAD artery.

Adjunct surgical procedures were enlargement of pulmonary trunk stenosis in 6 patients (associated with translocation of the great arteries in 1 patient), Brom aortoplasty in 3 patients, RV-PA conduit replacement in 2 patients, repair of aortic recoarctation in 1 patient, atrial septal defect closure in 1 patient, and the Ross operation in 1 patient.

\section{Postoperative Investigations}

Patients were followed at least every year, myocardial ischemia was documented on electrocardiograms, echocardiograms, and/ or myocardial perfusion images (thallium 201 scintigraphy at rest and during exercise or after injection of dipyridamole). Nineteen $(76 \%)$ of 25 patients undergoing CAPPA and $6(75 \%)$ of 8 patients undergoing $\mathrm{CABG}$ patients underwent selective coronary artery angiography through the femoral arterial approach after achievement of local anesthesia.

\section{Results}

Postoperative findings are shown in Table 2.

\section{Hospital Events}

Patient 18 had a persistent myocardial ischemia after ASO, with aortic root angiography showing equivocal results. He underwent an RCA arterioplasty 4 weeks later. He could be weaned from CPB, but both ventricles remained severely hypokinetic, and the patient died 4 days later in the intensive care unit (ICU). Autopsy demonstrated a globally ischemic myocardium with patent coronary arteries. In patient 31 the postoperative course was difficult (11 days in the ICU), with necessary mechanical assistance: 4 days of left ventricular assist device support followed by 4 more days of intraaortic balloon pumping. Postoperative coronary angiography was not done. This patient remained in mild-to-moderate cardiac failure after hospital discharge because of ischemic cardiomyopathy. Postoperative recovery was uneventful in the other 31 patients, without any documented ischemic events during hospital stay. Mean length of stay in the ICU was $2.8 \pm 1.2$ days (range, 2-6 days) after CAPPA and $3.9 \pm$ 3.4 days (range, 1-11 days) after CABG.

\section{Follow-up}

One patient (no. 20) was lost to follow-up. Patient 32 died suddenly 3.5 months after surgical intervention despite an uneventful perioperative course. This patient had a previous operation to relieve a biventricular hypertrophic cardiomyopathy; echocardiographic analysis after revascularization showed a good left ventricular function and no residual ventricular outflow tract obstruction, and an autopsy was not done. All other patients were alive after a mean follow-up of $3.4 \pm 3.1$ years (range, 2.4 months to 11.2 years) for CAPPA and $4.4 \pm 2.8$ years (range, 11.2 months to 8.7 years) for CABG. Patients 12 and 22 underwent reoperations 2.6 and 5.7 years, respectively, after arterioplasty for restenosis of the LAD, with good patency of the repaired LMCA in both cases. They underwent coronary bypass, which led to a good result for patient 12 (patient 28) and to graft occlusion, diagnosed 3 years after reoperation, for patient 22 (patient 29). In the last patient, who presented with Williams syndrome, the LAD was found to be diffusely small during the CABG.

Eighteen (72\%) of 25 patients undergoing CAPPA had no symptoms and received no cardiac medication but antiplatelet therapy. Two (nos. 3 and 23) still required angiotensinconverting enzyme inhibitor therapy and presented with limited residual perfusion defects on myocardial perfusion imaging studies; echocardiographic analysis showed mild dilated cardiomyopathy in patient 3 and diastolic ventricular dysfunction with moderate mitral regurgitation in patient 23. The last patient presented with severe congestive heart failure before repair of anomalous left coronary artery originating from the PA and required 6 days of left ventricular assistance after this first operation; afterward, he had persistent 
left ventricular dysfunction. In a subset of 19 (76\%) patients undergoing CAPPA who underwent coronary angiography, $17(68 \%)$ presented with a good patency of the repaired main stem. Among the 4 patients who did not have postoperative angiography, 3 were symptom free.

Five (63\%) of 8 patients undergoing CABG had no symptoms. Among them, 2 presented with unsatisfying angiographic results: patient 30 had a diffuse narrowing of the arterial graft (string sign) without angina or myocardial ischemia on thallium studies. Patient 29 had a graft occlusion with a residual anterior perfusion defect. The LAD distribution was well collateralized from the RCA and the circumflex artery, and the left ventricular function was relatively preserved; in view of the previous 2 surgical procedures and absence of symptoms, a new revascularization procedure was not attempted. In patient 33, despite the fact that preoperative fluorodeoxyglucose-positron emission tomographic scanning showed myocardial viability, the severe left ventricular dysfunction did not improve after the operation; angiographic analysis 3 months after revascularization revealed a tight stenosis at the distal anastomotic site, which was not accessible to a percutaneous angioplasty, and this patient was treated medically.

The last myocardial scintigram and the last coronary angiogram were obtained at an average of $3.7 \pm 3.0$ years (range, 2 months to 9.1 years) and $2.2 \pm 1.7$ years (range, 20 days to 5.1 years) after the operation, respectively.

\section{Discussion}

Our midterm functional and anatomic results with surgical arterioplasty of main stem coronary arteries in infants and children, mainly after the ASO, are good. Follow-up coronary angiograms were satisfying in $17(71 \%)$ of 24 survivors, and revascularization restored a normal myocardial perfusion in most cases. On the other hand, results after CABG were more disappointing.

Between 1987 and 2006, 755 neonates underwent an ASO at our institution (same surgeon). Among 713 late survivors, $290(41 \%)$ had at least 1 selective coronary angiogram, which showed coronary obstruction in 34 patients. $^{3}$ Among them, 15 patients did not have surgical revascularization either because surgical intervention was deemed impossible or hazardous ( 2 patients) or because there was, at that time, no evidence of myocardial ischemia (13 patients). ${ }^{3}$ A previous study, also from our institution, reported 36 coronary events in 34 patients after 432 consecutive ASOs (study period, 1987-1999). Coronary events included 16 fatal and 9 nonfatal myocardial infarctions and 12 reoperations. ${ }^{9}$ Coronary imaging after ASOs consisted of selective coronary angiography and was performed for one of the following reasons: (1) presence of electrocardiographic signs, echocardiographic signs, or both suggestive of myocardial ischemia any time after the operation; (2) presence of unusual coronary patterns (coronary arteries coursing between the great arteries) or intraoperative difficulties in coronary transfer, usually during the first postoperative year; (3) use of a single-orifice technique for coronary reimplantation; and (4) routinely in all patients before 5 years old, in the current era. Although detailed anatomy of the obstructed coronary artery and collateral vessels can be obtained by means of selective angiographic analysis, this procedure carries a certain amount of risk for the patient. ${ }^{10}$ On the other hand, multislice computed tomography is a relatively noninvasive technique that proved effective in detecting ostial and proximal coronary lesions after the ASO in a recent study. ${ }^{11}$ Thus our current policy is to perform coronary imaging by using coronary angiography, multislice computed tomographic angiography, or both in the situations listed earlier, and because the lesions are most probably progressive, those tests should be repeated at regular intervals during late follow-up after ASOs.

In many cases coronary obstruction was found in asymptomatic patients, and surgical intervention was delayed as long as there was no clear evidence of myocardial ischemia, either at rest or under stress conditions. Our study shows that coronary lesions after the ASO can be successfully enlarged by means of surgical arterioplasty with low operative mortality (there was 1 perioperative death in the CAPPA group). Thereafter, to prevent potential sudden death and to preserve ventricular function, one can speculate whether myocardial revascularization should be done as soon as coronary obstruction is diagnosed, even in the absence of obvious ischemia. However the long-term patency rate of this procedure and the fate of the patch material remain to be evaluated. The patient who died in the CAPPA group (no. 18) had previously had a neonatal ASO and remained in poor hemodynamic condition for 4 weeks after the operation because of persistent myocardial ischemia. Clinical features were misleading, and both diagnosis of coronary obstruction and revascularization came too late. The ventricles had already suffered irreversible ischemic damage at the time of reoperation, and death resulted from biventricular incompetence, despite patent coronary arteries.

Few studies have reported the use of CAPPA in pediatric patients. With 10 patients, our institution reported 8 years ago the largest series of this procedure in children. ${ }^{12}$ Since then, a few authors have reported its use in various indications. Prêtre and Turina ${ }^{13}$ operated on 3 children for coronary obstruction after the ASO, LMCA stenosis associated with supravalvar aortic stenosis, and a sequel of Kawasaki disease, with good results in each case. One author has reported a successful arterioplasty using a "pantaloon"-shaped autologous pericardial patch to enlarge a stenosis involving both the LMCA and RCA originating from a single ostium, which was obstructed after an ASO. ${ }^{14}$

In adult patients this technique is used for atherosclerotic lesions, with good results provided that some selection criteria are respected: patients with isolated noncalcified lesions confined to the proximal half of the coronary trunk are the 
best candidates. ${ }^{13,15}$ Meseguer and colleagues ${ }^{16}$ also reported that stenoses extending into the LMCA branches are at greater risk for thrombosis after proximal coronary arterioplasty. In our study, among the 3 patients in whom the incision was extended to the LAD coronary artery because of ostial or proximal stenosis of this artery, 2 (nos. 12 and 22) presented with a restenosis of the LAD that necessitated a coronary bypass. One hypothesis is that injury to the LAD can lead to constrictive vascular remodeling, as observed after balloon angioplasty. ${ }^{17}$ However, in patient 22 with Williams syndrome, the stenosis might be related to the progressive luminal narrowing that complicates the arteriopathy of the syndrome. Indeed, for this patient, the internal thoracic artery bypass also led to graft occlusion.

We never used, even in the less favorable cases of coronary arterioplasty, a combination of CAPPA and CABG in the same patient. Mavroudis and associates ${ }^{18}$ reported using this method in 4 patients. For 2 of them, the early postoperative angiographic studies were satisfying, whereas the repeat coronary angiograms 2 and $2^{4} / 2$ years later showed a string sign of the internal thoracic artery in both patients, with a good patency of the repaired left main trunk. The 2 other patients had a good early anatomic result but no late angiographic restudy. ${ }^{18}$ It is of course difficult to draw conclusions with only 4 patients, but it could be argued that in this setting the bypasses were probably unnecessary, at least for the 2 patients who had the string signs. They also indicate the use of the autologous aortic or PA wall because of the ease of manipulation and genetic homogeneity of this material. ${ }^{18}$ We mainly used a saphenous vein patch. Long-term follow-up should help us to determine the type of material that is best applicable for this purpose.

CABG with the ITA is technically feasible in small infants and children, ${ }^{5,19}$ with good results. ${ }^{18}$ In the patients reported on here, CABG led to unsatisfying results, with only $5(63 \%)$ of 8 patients in good functional status, $3(38 \%)$ of 8 patients with good angiographic results, and 1 patient with unexpected late death. Proportionately, patients in this group were in worse preoperative or perioperative states than patients in the CAPPA group. Three patients had at least 2 previous major operations, including 2 who had a failed myocardial revascularization (nos. 28 and 29) and 1 who had a very poor cardiac status before the operation (no. 33); the last patient continued to have severe heart failure after the operation. The patient who had an emergency CABG presented with a myocardial infarction with severe impairment of ventricular function during the operation, which incompletely improved afterward. Similarly, in the study by Mavroudis and associates, ${ }^{18}$ patients with severe ventricular insults during previous operations or catheterization exhibited poor improvement in ventricular function after surgical revascularization, despite patent bypass grafts. Finally, 3 patients in our study, including the one with severe cardiac failure (no. 33), exhibited unsatisfying angiographic results.
First was a graft occlusion (patient 29). The occluded LITA was grafted on a small LAD, probably related to a Williams syndrome arteriopathy. The patient was asymptomatic afterward, and collateral vessels probably had time to develop before the graft became blocked.

Second was a string sign or diffuse narrowing of the LITA, with a target LAD artery exhibiting a $75 \%$ to $90 \%$ narrowing on preoperative angiographic analysis (patient 30). This patient did not have angina or myocardial ischemia on thallium imaging after the string sign. In a multicenter randomized study 2 factors were independently associated with the emergence of a string sign on grafted radial arteries: perioperative use of $\alpha$-adrenergic agonists and target vessel stenosis of less than $90 \% .^{20}$

Finally, a tight anastomotic stenosis happened in a patient who had several previous operations and in whom the dissection of the LAD artery was difficult (patient 33). Furthermore, the conduit was unusual (free left subclavian artery) because both ITAs were unusable.

\section{Conclusions}

Surgical patch arterioplasty of the main coronary trunks could adequately enlarge coronary lesions complicating a previous coronary transfer, with low operative mortality. Provided that the branch coronary arteries, especially the LAD, were not involved in the stenotic process, it led to a good midterm patency rate and clinical functional status, and it often restored a normal myocardial perfusion, as assessed by means of perfusion imaging.

Internal thoracic artery bypass should be reserved for more distal lesions, long and complete occlusions of the main stem, or residual obstruction after primary surgical arterioplasty. In our series this procedure led to disappointing results, probably favored by the fact that indications in this group of patients were not as homogeneous as in the arterioplasty group.

\section{References}

1. Legendre A, Losay J, Touchot-Koné A, et al. Coronary events after arterial switch operation for transposition of the great arteries. Circulation. 2003;108(suppl II):II186-90.

2. Bonhoeffer P, Bonnet D, Piéchaud J-F, et al. Coronary artery obstruction after the arterial switch operation for transposition of the great arteries in newborns. J Am Coll Cardiol. 1997;29:202-6.

3. Raisky O, Bergoend E, Agnoletti G, et al. Late coronary artery lesions after neonatal arterial switch operation: results of surgical coronary revascularization. Eur J Cardiothorac Surg. 2007;31:894-8.

4. Kitamura S, Kawashima Y, Fujita T, Mori T, Oyama C. Aortocoronary bypass grafting in a child with coronary artery obstruction due to mucocutaneous lymph node syndrome: report of a case. Circulation. 1976;53: 1035-40.

5. Kitamura S. The role of coronary bypass operation on children with Kawasaki disease. Coron Artery Dis. 2002;13:437-47.

6. Yacoub MH, Radley-Smith R. Anatomy of the coronary arteries in transposition of the great arteries and methods for their transfer in anatomic correction. Thorax. 1978;33:418-24.

7. Vouhé PR, Haydar A, Ouaknine R, et al. Arterial switch operation: a new technique of coronary transfer. Eur J Cardiothorac Surg. 1994; 8:74-8. 
8. Bonnet D, Bonhoeffer P, Piéchaud JF, et al. Coronary obstructions after reimplantation of the two coronary ostia in a single orifice during arterial switch operation for transposition of the great arteries. Eur J Cardiothorac Surg. 1996;10:482.

9. Prêtre R, Tamisier D, Bonhoeffer P, et al. Results of the arterial switch operation in neonates with transposed great arteries. Lancet. 2001;357: 1826-30.

10. Vitiello R, McCrindle BW, Nykanen D, Freedom RM, Benson LN. Complications associated with pediatric cardiac catheterisation. $J \mathrm{Am}$ Coll Cardiol. 1998;32:1433-40.

11. Ou P, Mousseaux E, Azarine A, et al. Detection of coronary complications after the arterial switch operation for transposition of the great arteries: first experience with multislice computed tomography in children. J Thorac Cardiovasc Surg. 2006;131:639-43.

12. Bonnet D, Bonhoeffer P, Sidi D, et al. Surgical angioplasty of the main coronary arteries in children. J Thorac Cardiovasc Surg. 1999;117: 352-7.

13. Prêtre R, Turina MI. Surgical angioplasty of the left main coronary artery in non-atherosclerotic lesions. Heart. 2000;83:91-3.

14. Prifti E, Bonacchi M, Luisi SV, Vanini V. Coronary revascularization after arterial switch operation. Eur J Cardiothorac Surg. 2002;21:111-3.

15. Dion R, Elias B, El Khoury G, et al. Surgical angioplasty of the left main coronary artery. Eur J Cardiothorac Surg. 1997;11:857-64.

16. Meseguer J, Hurle A, Fernandez Latorre F, et al. Left main coronary artery patch angioplasty: midterm experience and follow-up with spiral computed tomography. Ann Thorac Surg. 1998;65:1594-7.

17. Faxon DP, Coats W, Currier J. Remodeling of the coronary arteries after vascular injury. Curr Opin Cardiol. 1997;12:468-74.

18. Mavroudis C, Backer CL, Duffy E, Pahl E, Wax DF. Pediatric coronary artery bypass for Kawasaki, congenital, post arterial switch, and iatrogenic lesions. Ann Thorac Surg. 1999;68:506-12.

19. Mavroudis C, Backer CL, Muster AJ, et al. Expanding indications for pediatric coronary artery bypass. J Thorac Cardiovasc Surg. 1996; 111:181-9.

20. Miwa S, Desai N, Koyama T, Chan E, Cohen EA, Fremes SE. Radial artery angiographic string sign: clinical consequences and the role of pharmacologic therapy. Ann Thorac Surg. 2006;81:112-9.

\section{Discussion}

Dr Carl L. Backer (Chicago, Ill). Dr Bergoënd, I congratulate you on a very nice presentation. You and your colleagues have presented what I believe is the largest series reported to date of CAPPA. You have also shared with us a smaller experience with coronary bypass grafting in children. You have presented a total of 33 children undergoing myocardial revascularization, 25 with a proximal coronary artery patch, and the most common indication was postarterial switch in 21 patients. Given your overall arterial switch experience of nearly 500 patients, this looks like an incidence of about $4 \%$. You concluded that the results with the patch are quite good, but you were disappointed with the results of CABG, with only $38 \%$ of the patients having a good postoperative angiogram.

Our series at Children's Memorial Hospital is essentially, and interestingly, the mirror image of your series, probably reflecting a different patient population and pathology at presentation. In the past 20 years, Gus Mavroudis and I have done 27 CABGs and only 5 proximal coronary artery patches. In our series the most common indications were Kawasaki disease, which was present in 9 patients; postarterial switch or the Ross procedure, which was present in 7 patients; and congenital coronary anomalies, which were present in 6 patients. We had 3 deaths, very similar to your series, but the patency rate of coronary bypass grafting in our long\%2011term evaluation was $88 \%$. I guess I would agree with you that in your series the disappointing results with coronary bypass grafting is probably due to the small number of patients and the varying indications.
However, I believe it remains a very important strategy for some patients in whom a patch is not an option.

I have 4 questions for you. The first relates to the number of patients undergoing ASO in your series who had coronary stenosis. It appears that we have created a new disease. My question for you is this: Do you believe that all the patients who have an ASO should have sophisticated coronary imaging, such as coronary angiography, as part of their routine long-term follow-up at, for instance, $2,3,5$, or 10 years of age? What are your thoughts on that?

Dr Bergoënd. We are doing coronary evaluation by means of selective coronary angiography and computed tomography. We do it early after the operation if the patient has signs of myocardial ischemia on electrocardiographic or echocardiographic analysis. We do it routinely during the first postoperative year if the patient presented with an unusual coronary pattern, like coronary arteries coursing between the great arteries, or if the coronary transfer was difficult during the operation. We are doing it also on a systematic basis for all the patients before the age of 5 years because we had quite a high number of patients who were fully asymptomatic at the time of diagnosis. The diagnosis was made based on routine coronary angiographic analysis, with no signs suggestive of myocardial ischemia either on electrocardiographic or echocardiographic analysis.

For our latest patients, we are doing only 64-slice computed tomography because it is a reliable study to detect proximal coronary lesions, and it is less invasive than standard coronary angiography.

Dr Backer. I think that is an excellent solution. We recently installed one of those scanners, and I think that really is the answer for these patients. I personally think they should probably all have that evaluation. I noticed that some of the patients in your series had a complete occlusion of the coronary artery, and yet they were asymptomatic.

My second question also relates to this postarterial switch complication. Do you have any insight into this problem of coronary stenosis after the ASO, and have you changed your operative technique for patients undergoing ASOs to attempt to prevent this late complication, be it in only $4 \%$ of your patients?

Dr Bergoënd. We have indeed quite a high number of coronary complications after ASOs. For some of the patients in this series, it was related to a particular technique of coronary transfer in which the coronary arteries were reimplanted side by side in the neoaorta. This technique is associated with a very high incidence of coronary obstruction in the long term, and therefore it was abandoned. For the other patients, we did not have, during the operation, a clear and satisfying explanation for the stenosis.

Dr Backer. My third question relates back to our series in which we, in some cases, were not always completely satisfied with the proximal patch and we were concerned enough intraoperatively to also do a coronary bypass graft; therefore both the patch and the bypass were used, somewhat like a "belt-and-suspenders" approach. We used this approach in 4 patients. After reading your manuscript and hearing your presentation, your excellent results with the patch make me think that perhaps this was unnecessary, although you did have 1 death in your series in which the patient probably died from postoperative myocardial ischemia. Do you have any thoughts about this approach, and have you used this "belt-and-suspenders" technique in any of your cases?

Dr Bergoënd. No, we did not do it in our experience. The patient who died after arterioplasty had a very severe left ventricular dysfunction after the ASO, and during the autopsy, the coronary arteries 
were patent. Therefore I do not know whether it is a real failure of the arterioplasty.

Dr Backer. My final question is this: What is your anticoagulation protocol after the coronary patch or the bypass?

Dr Bergoënd. Antiplatelet therapy.

Dr Backer. Aspirin?

Dr Bergoënd. Lifelong.

Dr Backer. Congratulations on an outstanding series, and thank you for the privilege of discussing this paper.

Dr Soichiro Kitamura (Osaka, Japan). I just want to make a comment. I have experience with more than 100 cases of bypass operations using arterial grafts for children. As you know, the patency or closure of a string sign on a bypass graft, like an arterial graft, such as the ITA, depends on the length and grade of the stenosis. Therefore it is a crucial point to select the methodology to revascularize the coronary arteries in children.

I would like to ask you a question. Both series have a similar length and grade of stenosis. Then the patency rate is also $88 \%$, which is similar to our patency rate of the arterial grafts to the children's coronary artery obstruction. If you select the case, the coronary ostial stenosis, after ASO, the patch enlargement of the coronary ostium will be better than after a bypass graft. But for the other stenosis, the length of the left main trunk is obstructed almost more than a few millimeters, and the bypass will be much better I think. So I just want to ask you: In your 2 series, are grade and length of the stenosis similar?

Dr Bergoënd. Yes, they were similar. But for the patient who had the string sign, the stenosis was on the LAD originating from the RCA, and the stenosis was between $75 \%$ and $90 \%$, and therefore this is probably the reason why the string sign developed.

But I agree with you we should have strict indications for arterioplasty and coronary bypass. For arterioplasty, it should be a short and proximal lesion, and the LMCA bifurcation should not be involved. Probably for the other patients, the internal thoracic artery bypass would be better.

Dr Kitamura. So I understand, your 2 series are heterogenous?

Dr Bergoënd. Yes, they are heterogenous.

Dr Kitamura. For my final comment, if there is an anastomotic stenosis with the ITA graft, just a simple balloon enlargement would be enough, no stent is necessary with children. And the decrement is very rare. Just a simple dilatation of the balloon is sufficient for ITA coronary bypass.

Dr Bergoënd. For the patient who had a distal anastomosis stenosis, it was not possible to do balloon dilatation.

Dr Bohdan Maruszewski (Warsaw, Poland). Congratulations on your paper. Excellent results.

When you look at your postswitch coronary ostial stenosis, can you tell us what is the anatomy - the original anatomy - of the coronary arteries that predisposes to the late stenosis? For example, do you agree that a dominant RCA with a separate ostium of the LAD predisposes to the late stenosis of the LAD?

Dr Bergoënd. In our series of 21 patients after the ASO, 14 had the usual coronary pattern, 6 had a coronary pattern with a loop around one great artery (it is D and E from Yacoub classification), and 1 had the coronary artery crossing between the arteries.

Dr Maruszewski. So a pretty mixed anatomy?

Dr Bergoënd. Yes. 